\title{
Zero Runoff dan Konservasi Air Tanah Melalui Pemanfaatan Paving Block Biopori di Kawasan Permukiman
}

\author{
Ery Setiawan, Sasmito, Heri Sulistiyono, Desi Widianty, Syamsul Hidayat \\ Jurusan Teknik Sipil, Universitas Mataram, Mataram, Indonesia;
}

Alamat korespondensi:ery.setiawan@unram.ac.id

\begin{abstract}
ABSTRAK
Zero runoff identik dengan suatu upaya untuk meminimalisir limpasan akibat hujan di permukaan lahan. Upaya ini digunakan sebagai bentuk mempercepat waktu kuras limpasan di dalam kawasan permukiman yang saluran drainasenya kurang berfungsi maksimal. Solusi untuk zero runoff di permukiam adalah menggunakan media lubang biopori. Lubang biopori merupakan salah satu bentuk teknologi tepat guna multifungsi, karena dapat mengurangi limpasan hujan sekaligus untuk konservasi air tanah dengan cara meresapkan air ke dalam tanah melalui lubang-lubang yang dibuat dengan ukuran tertentu. Bahan paving block bertujuan agar pekarangan/lahan menjadi rapi, bersih dan rata, namun mengurangi kemampuannya meresapkan air ke dalam tanah menjadi berkurang. Oleh karena itu dibutuhkan paving block biopori, yaitu paving block yang diberi lubang berukuran tertentu. Metode ini sangat cocok disosialisasikan dan diterapkan di pemukiman padat penduduk di suatu kawasan perkotaan. Hasil riset pendahuluan menunjukkan, bahwa lubang biopori mampu mereduksi genangan air akibat limpasan air hujan sebesar $\pm 15 \%$ di awal musim hujan dan menurun menjadi \pm $2 \%$ di akhir musim hujan, dengan laju peresapan air per lubang 3 liter/menit di awal musim hujan dan menurun menjadi \pm 0,4 liter/menit di akhir musim hujan. Kegiatan sosialisasi dan penyuluhan tentang zero runoff dan biopori mampu meningkatkan pengetahuan warga masyarakat tentang cara pembuatan lubang biopori secara mandiri dan berbagai manfaatnya yang multifungsi.
\end{abstract}

Kata kunci: resapan, reduksi, limpasan, multifungsi dan ramah lingkungan

\section{PENDAHULUAN}

Perubahan tutupan lahan di permukiman dapat meningkatkan limpasan permukaan lahan, sementara di satu sisi kapasitas dan kemampuan drainase tidak berubah, sehingga menjadi kurang optimal (Suripin, 2004). Paving block adalah bahan perkerasan tutupan lahan yang berpori, namun kemampuan resapannya sangat terbatas, sehingga sekarang ini banyak dibuat dan dikembangkan modifikasi paving block dengan kombinasi lubang dengan ukuran dan bentuk lubang tertentu yang disebut sebagai paving block biopori (Nihayah, 2020, Fiki, 2020). Zero runoff didefinisikan sebagai upaya untuk meminimalisir limpasan akibat hujan di permukaan lahan (Suripin, 2004, Castro, dkk., 2007). Salah satu solusi untuk menerapkan zero runoff di permukiman adalah dengan menggunakan media biopori. Biopori adalah salah satu bentuk implementasi kegiatan konservasi lingkungan multifungsi, karena mampu mengurangi limpasan hujan, mempercepat waktu kuras (time to drain) sehingga membantu mengurangi genangan sekaligus konservasi air tanah. Metode ini sangat cocok disosialisasikan dan diterapkan di pemukiman padat penduduk di suatu kawasan perkotaan/perumahan (Castro dkk., 
2007). Beberapa hal yang menjadi persyaratan untuk menempatkan dan membuat biopori di lahan permukiman adalah sebagai berikut : kondisi muka air tanah di lokasi tersebut cukup dalam, hal ini dicirikan dengan kondisi air sumur dalam atau permukaan air sungai dalam, jenis tanah bukan lempung, tergantung musim (intensitas hujan), luas area, ukuran dan jumlah biopori.

Tujuan kegiatan ini adalah agar masyarakat semakin banyak mengenal dan memahami zero runoff serta multifungsi teknologi biopori dan akhirnya akan menjadi budaya di masyarakat untuk melakukannya. Sasaran kegiatan ini adalah kelompok masyarakat di dalam permukiman atau perkotaan.

\section{METODE KEGIATAN}

Kegiatan ini adalah kegiatan pengabdian masyarakat berbasis penelitian, sehingga metode yang dilakukan adalah sebagai berikut :

1. Tahapan riset pendahuluan yang berlokasi di Laboratorium Hidrolika dan Laboratorium Bahan Jurusan Teknik Sipil, Universitas Mataram. Alat dan bahan yang digunakan antara lain adalah : rainfall simulator \& alat ukurnya, lahan uji, sampel tanah, model paving bock berpori, tandon air, selang, kran, tabung penampung, stop watch, meteran \& alat ukur lain. Gambar 1 menyajikan uji riset pendahuluan di laboratorium JTS dengan benda uji berupa paving block biopori.

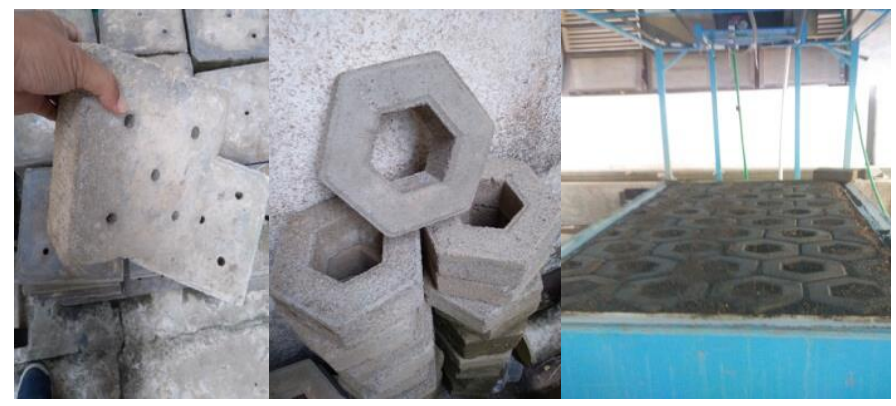

Gambar 1 Tahap riset pendahuluan di JTS.

2. Tahapan sosialisasi/penyuluhan dilakukan dengan tujuan agar lebih mengenalkan biopori, cara pembuatan dan manfaatnya. Lokasi sosialisai dan penyuluhan di Labuapi, Lombok Barat yang dihadiri warga masyarakat kelompok peduli lingkungan. Metode penyuluhan dengan menggunakan alat bantu peraga berupa bor tanah/hand bor tipe pisau ulir, ditambah dengan gambar penjelas berupa slide, foto dan video. 


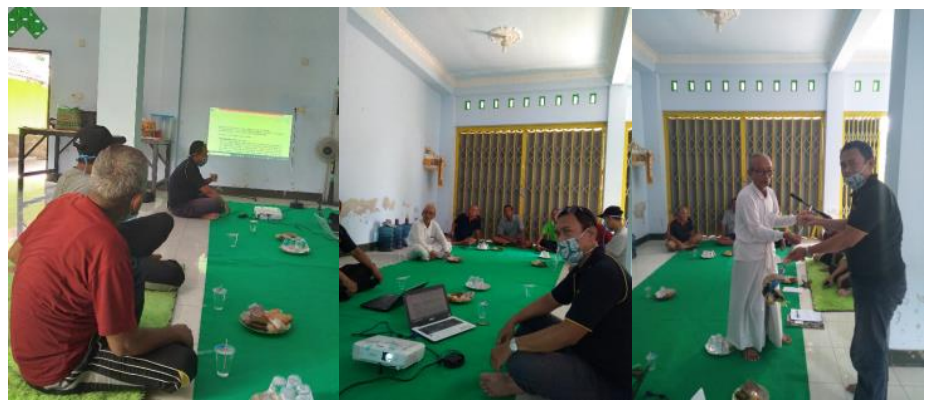

Gambar 2 Tahap sosialisasi dan penyuluhan di Labuapi, Lombok Barat.

3. Tahapan implementasi dan uji coba di lapangan Lokasi : perumahan di Labuapi, Lombok Barat. Alat dan bahan : PVC 4 inc, bor listrik $5 \mathrm{~mm}$, bor tanah/hand bor tipe ulir dan lingkaran, alat potong, paving bock berpori dan/atau penutup dari pralon.

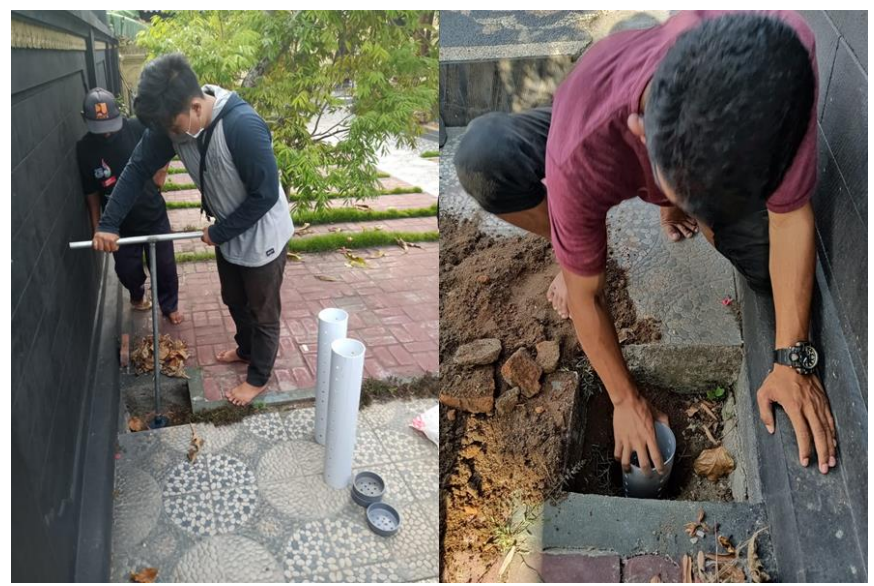

Gambar 3 Tahap implementasi lapangan di Labuapi, Lombok Barat.

\section{HASIL DAN PEMBAHASAN}

Hasil riset pendahuluan menunjukkan, bahwa lubang biopori mampu mereduksi/mengurangi genangan air akibat limpasan air hujan rerata sebesar $\pm 15 \%$ di awal musim hujan dan menurun menjadi $\pm 2 \%$ di akhir musim hujan. Laju peresapan air/infiltrasi \pm 3 liter/menit di awal musim hujan dan menurun menjadi $\pm 0,4$ liter/menit di akhir musim hujan atau sekitar $\pm 38 \mathrm{~cm} /$ menit di awal musim hujan dan $\pm 5 \mathrm{~cm} /$ menit di akhir musim hujan. Gambar 4 menyajikan rerata laju resapan/infiltrasi air limpasan hujan pada 2 kondisi berbeda.

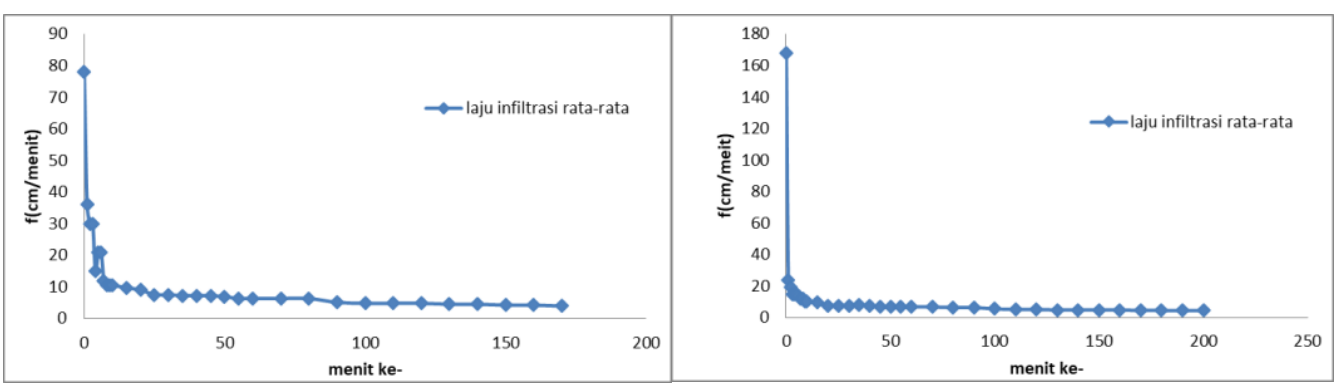

Gambar 4 Hubungan laju resapan/infiltrasi terhadap waktu. 


\section{KESIMPULAN DAN SARAN}

1. Secara umum pelaksanaan penyuluhan/sosialisasi telah berjalan lancar sesuai dengan rencana jadwal. Kegiatan penyuluhan telah mampu meningkatkan pengetahuan warga masyarakat peserta tentang manfaat, cara pembuatan dan kinerja biopori.

2. Implementasi biopori di lokasi masih dalam tahap pemantauan/pengamatan, karena sampai sejauh ini (masih di pertengahan musim hujan) menunjukan kinerja yang cukup efektif. Disarankan untuk implementasi di lapangan diamati sampai dengan akhir musim hujan (sekitar bulan April) untuk melihat performa/unjuk kerja dari biopori.

3. Jenis tanah dan kedalaman air tanah menjadi faktor penentu performa/kinerja biopori, sehingga sebelum eksekusi terhadap biopori perlu dilakukan investigasi terhadap kedua faktor tersebut.

\section{UCAPAN TERIMA KASIH}

Penulis mengucapkan terima kasih kepada LPPM Universitas Mataram yang telah memberi dukungan finansial terhadap kegiatan pengabdian ini, melalui Dana Internal Hibah Pengabdian PNBP Universitas Mataram tahun 2020.

\section{DAFTAR PUSTAKA}

Castro, D., Angullo, G., Rodriuez., J., and Calzada, M, A., 2007. The Influence of PavingBlock Shape on the Infiltration Capacity of Permeable Paving. Departemento de Transportes, Universidad de Cantabria Spain.

Fiki Dinan Atsmara, 2020, Penambahan Lubang Pori Pada Paving Block Dalam Upaya Mengurangi Limpasan Air Permukaan, Jurusan Teknik Sipil Universitas Mataram.

Nihayah, 2020, Model Eksperimental Pengaruh Grass Block Paving Terhadap Limpasan Permukaan, Jurusan Teknik Sipil Universitas Mataram.

Suripin. 2004, Sistem Drainase Perkotaan yang Berkelanjutan. Andi. Yogyakarta. 